\title{
Rates and causes of mortality in a fragmented population of Iberian lynx Felis pardina Temminck, 1824
}

\author{
P. Ferreras, J. J. Aldama, J. F. Beltrán \& M. Delibes \\ Estación Biologica de Doñana, CSIC, Apdo. 1056, 41080 Sevilla, Spain
}

\begin{abstract}
Data are presented on mortality rates of the Iberian lynx Felis pardina in Doñana National Park and the surrounding area in southwestern Spain, collected from 1983 to 1989. Data from radio-tagged lynxes and records of lynx mortality were used to assess causes of death. Annual mortality rate, estimated by using the Heisey and Fuller methodology, was 037. Human activities were the main cause of lynx mortality in this mainly fully protected area, either directly (illegal trapping: $417 \%$; road traffic: $167 \%$; hunting with dogs: $83 \%$ ) or indirectly (artesian wells: $8.3 \%$ ). Only $83 \%$ of the annual mortality can be related unequivocally to natural causes. Sex, age, social status, year, and home range situation influenced mortality rates. The trend of this lynx population during the seven years of study revealed serious threats to its survival. This case study exemplified how a small population can approach extinction because of increased mortality due to habitat fragmentation, despite full protection of the main portion of its range.
\end{abstract}

\section{INTRODUCTION}

Many authors have referred to the extinction of species caused by habitat fragmentation (Lovejoy et at., 1984; Diamond 1989). However, there are few descriptions of the extinction process of these fragmented populations. In this paper we analyse the mortality of an isolated and fragmented population of Iberian lynx Felis pardina in risk of extinction (Palomares et aL, 1991).

The Iberian lynx is considered the most endangered carnivore in Europe (Mallinson, 1978). The total population has been estimated to be about 1000 individuals, distributed in many small and isolated populations in the southwestern Iberian Peninsula (Rodriguez \& Delibes, 1992). The Dofiana lynx population was estimated at $40-50$ individuals in 1987 (Palomares et a!., 1991), its range including the protected Dofiana National Park $(550 \mathrm{~km} 2)$ and the recently created Dofiana Environment Natural Park (540 km2).

Nevertheless, this lynx population has recently decreased in numbers (Rau et at., 1985; Palomares et a!., 1991). Hence, it is important to know the rates and causes of mortality, in order to attempt to reduce them.

The objectives of this study were fourfold:

(1) to estimate annual mortality rate of the Doflana lynx population from 1983 to 1989;

(2) to estimate differential mortality rates by sex, age, social status, year and home range situation;

(3) to determine causes of mortality; and

(4) to discuss the ability of the current Doflana protected area to enhance lynx survival.

Estimation of mortality rate and anecdotal information on birth rates can allow us to speculate about the annual balance and trends of the Doflana lynx population, and assess management plans for the conservation of the Iberian lynx.

\section{STUDY AREA}

Located in southwestern Spain, the study area covers approximately $2750 \mathrm{~km} 2$, including Doflana 
Fig. 1. Sketch of the study area. Road C-445 is marked with an asterisk and the tourist urbanization with a double circle.

National Park $(550 \mathrm{~km} 2)$ and the recently created (1989) Natural Park of the Dofiana Environment (540 km2) (see Palomares et at 1991). There are many detailed descriptions of this zone (Amat et at, 1979; Rogers \& Myers, 1980). The Doflana area, flat and low, is on the western bank of the Guadalquivir river (Fig. 1). The area is also bordered on the south and west by the Atlantic Ocean, on the north by the alluvial plain of the Tinto river and the intensively cultivated high ground of the Aljarafe, and on the east by the Marismas of the Guadalquivir river.

The land bordering the protected area is under considerable human exploitation. A large development of coastal tourism (in the Matalascaflas urbanization), intensively cultivated (olive trees, vines) and irrigated (fruit trees and strawberries) lands, pine Pinus pinea plantations exploited for wood and edible pine seeds in the west and eucalyptus plantations in the north, have increased human pressure in the area in the last 25 years. Several roads connecting villages, especially the
C-445 from El Rocio to Matalascaflas, cross habitats normally occupied by lynxes.

Three lynx nuclei are distinguished by Palomares et at (1991) in the population under study: a large central one occurring mainly in the National Park, but effectively divided into two subnuclei by areas of open marsh and cultivation; a second in the northwest (Moguer), and the smallest one in the east (Puebla). The last two subpopulations are mainly in the unprotected area.

\section{METHODS}

Between 1983 and 1989 we radio-tagged 30 lynxes, representing 9523 transmitter-days (Delibes \& Beltrán, 1986). Animals were captured with trunktraps, box-traps and victor No. 2 coil-spring traps (Woodstream Co., USA) with cushioned jaws to avoid injuries. They were immobilized with a mixture of Ketamine and Xylazine, weighed, measured, equipped with radios, and samples of blood 


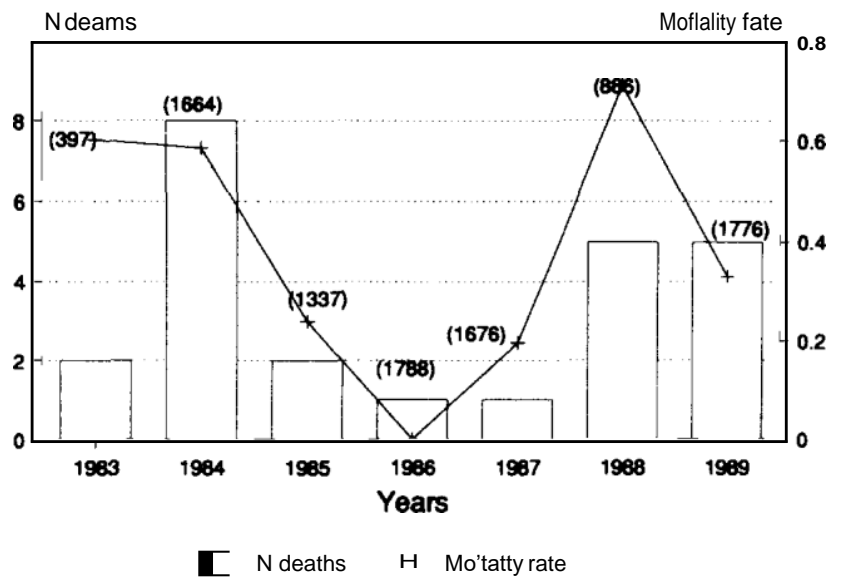

Fig. 2. Variation of the Annual Mortality Rate throughout the study period and number of total dead lynx (with and without transmitter) found each year. The number of radiotracking days are given in parentheses.

and exoparasites taken. Mortality rates were estimated using the MICROMORT program (Heisey \& Fuller, 1985), based on calculating daily mortality rates, according to the total number of radiotransmitter days and deaths of radio-tracked animals occurring in the interval covered (Trent \& Rongstad, 1974). The different rates were compared at the $\mathrm{p}<001$ level with the test proposed by these authors in the program manual. This employs a statistic based on the corresponding rate estimates, their variances and the covariance (all calculated by the program), and fits into a Z-normal distribution.

All records of dead lynxes in the Dofiana area in the period 1983-89 were used to estimate mortality causes and their relative importance.

Individual lynxes were separated into three age classes: juvenile (under one year old), subadult U-2 years old), and adult (over two years old), according to dentition, weight and other physical measurements (Beltrán, 1988). By using radiotracking data on the lynx space-use patterns, we have distinguished three social classes in the Dofiana lynx population: residents (individuals holding a permanent home range); dispersers (individuals with no established home range, frequently juveniles and subadults dispersing from their natal ranges, but also some adults ejected from their home ranges by competitors); and predispersant young (kittens and juveniles that live in their natal range) (Griffith \& Fendley, 1986; Delibes, 1989). Mortality rates were estimated for each class of age, sex and social status.

\section{RESULTS}

\section{Annual mortality rate}

Average annual mortality rate (AMR) from radiotracking data was $037 \pm 0025$ (mean \pm standard error) with high variability during the study period $(\mathrm{SD}=026$; Fig. 2), and significant differences between 1984 and $1986(\boldsymbol{Z}=320, \mathrm{p}=0001)$ and 1986 and 1989 ( $Z \quad 239, \mathrm{p}=0008$ ). Mortality seemed to be cyclical, with peaks in 1984 and 1988 and a minimum in 1986. Social status appeared to have the strongest effect on mortality rate (Table 1), dispersers having the highest mortality (male $\mathrm{AMR}=086$, female AMR = 070). As stated, dispersers included adults expelled from their territory (two cases, found dead in 1984 and 1987). Predisperser individuals had the lowest mortality rate, although in this group only individuals older than five months are included, since animals younger than this age cannot be fitted with a transmitter. None of the seven young male lynxes radiotracked died in their natal range, before dispers-

Table 1. Annual mortality rates (AMR), 95\% confidence intervals (CI), number of radio-tracking days (RD), number of tracked individuals (IND) and number of recorded deaths (DEA) by different categories of sex and social status

Sex and social status

AMR

$95 \%$

RD

IND

DEA

Confidence

interval

Resident male

Resident female

Predispersing male

Predispersing female

I)ispersing male

I)ispersing female

Total male

Total female

012
021
000
031
086
070
043
028

$\begin{array}{lr}000-0-32 & 2791 \\ 000-043 & 3110 \\ 000-000 & 1247 \\ 000-067 & \mathbf{9 7 4} \\ 033-097 & 1097 \\ 000-097 & 301 \\ 0-16-062 & 5135 \\ 001-048 & 4385\end{array}$

The total number of males and females does not coincide with the addition of numbers in each category because some individuals were tracked while belonging to different categories. 
Table 2. Causes of mortality: annual mortality rates (AMR) due to each cause, percentage (\%) of the total AMR, confidence intervals (CI), number of deaths for the radio-tagged sample (DEAR); total of deaths (DEAT) (tagged and not tagged) and percentage (\%) of total deaths due to each cause

\begin{tabular}{|c|c|c|c|c|c|c|}
\hline & \multicolumn{3}{|c|}{ Radiotagged } & \multicolumn{3}{|c|}{ Total } \\
\hline & AMR & $\%$ & CI $95 \%$ & DEAR & DEAT & $\%$ \\
\hline Illegal trapping & 015 & 417 & $003-028$ & 4 & 8 & 333 \\
\hline Road & 006 & 167 & $000-014$ & 2 & 5 & 208 \\
\hline Unknown & 006 & 167 & $000-014$ & 2 & 4 & 167 \\
\hline Wells & 003 & 83 & $000-009$ & 1 & 3 & 125 \\
\hline Natural & 003 & 83 & $000-009$ & 1 & 2 & 83 \\
\hline Dogs & 003 & 83 & $000-009$ & 1 & 1 & 42 \\
\hline Accident & & & & & 1 & 42 \\
\hline Total & 037 & & $018-051$ & 11 & 24 & \\
\hline
\end{tabular}

ing, and only one female out of the eight radiotagged individuals died (Table 1). Mortality rates were greater in males than in females, though not significantly $(Z=O 9 l, p=0184)$.

\section{Causes of death}

During the seven years of study we recorded 24 cases of dead lynxes (Table 2). The main cause of mortality in this period was accidental illegal trapping in coil-spring traps and snares set to catch foxes and rabbits. At least eight individuals were killed in this way, of which four had been radiotagged $($ AMR $=015)$. A female lynx with kittens was killed by a poacher with hunting dogs. The second most important cause of mortality was road traffic $(\mathrm{AMR}=006)$. Five lynxes were killed by cars on road $C-445$, which runs along the western limit of the National Park, crossing lynx habitats. At least three lynxes drowned in artesian wells (125\%, the first of these radio-tagged; after discovering it, we looked in other wells in the area and found two more). Four individuals were found dead from unknown causes (167\%). Another lynx was caught alive by men and probably died of stress (the 'accident' in Table 2). Two adult females died of starvation due to natural causes. One was radiocollared and was lame through arthrosis, while the other had two broken ribs probably due to being kicked by a red deer Cervus elaphus. Evidence of prey-caused mortality in wolves Canis lupus is given in Mech and Nelson (1990).

\section{DISCUSSION}

The AMR of the Doflana lynx population is high, and similar to the mortality of some harvested bobcat Felis rufus populations (e.g. Fuller et a!., 1985). This suggests that being categorized as an endangered species (IUCN, 1988), protected by Spanish law, and occurring in protected areas, does not guarantee the conservation of this feud.

Most lynx mortality in Doñana is caused by accidents related to human activities, with about 75\% of the AMR either directly (illegal trapping, road accidents, hunting with dogs) or indirectly (drowning in artesian wells) man-caused. This is a consequence of the high humanization of the area surrounding the National Park (a similar case is described by Mech (1989) for the wolf). Though illegal, the use of coil traps and snares to kill rabbits and foxes in many private properties bordering the National Park (mostly agricultural land) is common. Road traffic is also very high, especially in summer, because of intensive coastal tourism.

Inter-annual variations in mortality rates could be caused by changes in rabbit availability, as rabbits are the staple prey of Iberian lynx (Delibes, 1980), and rabbit breeding depends on weather conditions (Soriguer, 1981; Vandewalle, 1989). Scarcity of rabbits must favour lynx dispersal and then increase mortality rates. However, at present we are not able to demonstrate a cause - effect relationship between rabbit numbers and lynx mortality.

Fragmentation increases the number and length of edges (Laurence \& Yensen, 1991) and is associated with increased mortality risk to lynxes. The risk of living in the surrounding area is shown when the mortality rate of adult resident males (0.48, $n=566$ radio-transmitter days) in The Acebuche (a protected property by the western side of the Park bordered by the $C-445$ road) is compared with the mortality rate of adult males living in the Biological Reserve, in the middle of the park $(0 \bullet 00, n=2225$ radio-transmitter days). 
Fragmentation of good-quality habitats also explains the high mortality of dispersers, which are forced to cross high-risk habitats when looking for new areas to settle. It is interesting to note that females, which have shorter and more delayed dispersal movements than males (authors, unpublished data), have lower mortality rates than males, although this difference is not significant.

As noted, we have not radio-tagged individuals under five months of age. Hence, we do not know mortality rates of kittens under this age, although for some similar species, such as Felis lynx, this time is very critical (Kaczensky, 1990). We have only two records of dead lynx under five months old: one died of unknown causes, while the other was illegally trapped. Also field behaviour (activity movement patterns) of some radio-tagged lactating females seems to indicate high neonatal mortality (authors, unpublished data). On the contrary, mortality in predispersing individuals more than five months old is very low.

Based on radio-tracking data and anecdotal records of reproduction, we can speculate about birth rates and evaluate the extreme values of the annual balance of the Doñana lynx population, assuming it to be isolated (Palomares et aL, 1991; Rodriguez \& Delibes, 1992, this issue). We assume a mean population size of 45 individuals $(40-50$, according to the cited authors), with $10-13$ reproductive females. Female productivity will depend on food availability and other factors (diseases, predators, hazards), and will never exceed two young reaching five months of age per female per year. Using our estimated mean annual mortality rate from the radio-tagged sample (AMR037), the net annual increase will rarely reach nine individuals per year (the difference between the maximum total recruitment, $13 \times 2=26$ five monthold kittens, and the estimated number of deaths, $45 \times 037=167)$. However, in unfavourable years for breeding (when few or no females are able to breed or kitten mortality is very high), the population could lose 17 lynxes (the mean number of annual deaths), a third of its total number. These simple calculations suggest a pessimistic future for the Doñana lynx population, because the number of individuals lost in unfavourable years exceeds the potential increase in optimal ones.

Total protection of the lynx range in Doflana does not ensure the survival of the population. Some years ago, Dasmann (1983) stated that 'areas designated for nature conservation .... surrounded by lands used intensively .... may be in- adequate to provide for the survival of the species originally contained within them'. Our study corroborates this point of view and provides quantitative information to analyse the relationship between fragmentation, size and shape of a protected area, and mortality of a top predator. At Doñana, lynx are not being hunted toward extermination as happened in the past with Felis lynx in Central Europe (Eiberle, 1972). Rather, they are dying because of diverse human activities which are not directed against them (illegal trapping focused on foxes and rabbits). Most deaths occur during dispersal, when lynx cross the limits of the protected area. Conservation of biodiversity in the Doñana National Park, as illustrated in this case study of the Iberian lynx, requires a policy of nature and wildlife conservation throughout the region, not only inside the protected area, which is too small to hold a minimum viable population of the species (Shaffer \& Samson, 1985; Palomares et al., 1991). The recent creation of the Natural Park of the Doñana Surroundings is a necessary, but still insufficient, step forward.

\section{ACKNOWLEDGEMENTS}

This study has been supported by the CAICYTCSIC (project No. 944), FONDENA-WWF Spain and the DGICYT-CSIC (project No. PB87-0405). We thank R. Laffitte, who has performed almost all the captures and tracked the lynxes. We are also grateful to N. Bustamante for English correction. Dr P. Jackson, Dr E. Heligren and an anonymous referee have kindly commented on the manuscript.

\section{REFERENCES}

Amat, J. A., Montes del Olmo, C.. RamIrez Djaz, L., Torres Ramirez, A. (1979). Parque Nacional de Doñana. Mapa ecologico. ICONA, Madrid.

Beltrán, J. F. (1988). EcologIa y conducta espacio-temporal del lince ibérico (Lynx pardina Temminck, 1824) en el Parque Nacional de Doñana. PhD thesis, University of Seville.

Dasmann, R. F. (1983). The relationship between protected areas and indigenous peoples. In Proceedings of the World Congress on National Parks. ed. J. A. McNeely \& K. R. Miller. IUCN, Gland, Switzerland, pp. 667-71.

Delibes, M. (1980). Feeding ecology of the Spanish lynx in the Coto Dofiana. Acta Theriologica, 25(24), 309-24.

Delibes, M. (1989). Factors regulating a natural population of Iberian lynxes. Conf Reintroductions of Predators in Protected Areas, Torino, Italy, 1987, pp. 96-9. 
Delibes, M., Beltrãn, J. F. (1986). Radio-tracking of six species of carnivores in the Donana National Park, SW Spain. Mesogée, 46, 113-20.

Diamond, J. (1989). Overview of recent extinctions. In Conservation for the Twenty-first century, ed. D. Western \& M C. Pearl. Oxford University Press, New York \& Oxford, pp. $37-41$.

Eiberle, K. (1972). Lebensweise und Bedeutung der Luchses in der Kulturlandschaft. Mammalia Depicta, No. 8. Paul Parey, Hamburg, Berlin.

Fuller, T. K., Berg, W. E. \& Kuehn, D. W. (1985). Survival rates and mortality factors of adult bobcats in north-central Minnesota. J. Wild!. Manage., 49, 292-6.

Griffith, M. A. \& Fendley, T. T. (1986). Pre and post dispersal movement behaviour of subadult bobcats of the Savannah River Plant. In Cats of the World: Biology, Conservation and Management, ed. S. D. Miller \& D. D. Everett. National Wildlife Federation, Washington, pp. 27789.

Heisey, D. M. \& Fuller, T. K. (1985). Evaluation of survival and cause-specific mortality rates using telemetry data. $J$. Wild!. Manage., 49, 668-74.

IUCN (1988). 1988 IUCN Red List of Threatened Animals. IUCN, Gland.

Kaczensky, P. (1990) Beaucoup de lynx périssent jeunes. Infodienst Wildbiologie, No. 3.

Laurence, W. F. \& Yensen, E. (1991). Predicting the impacts of edge effects in fragmented habitats. Biol. Conserv., 55, 93-103.

Lovejoy, T. E., Rankin, J. M., Bierregaard, P. O., Brown, Jr K. S., Emmons, L. H. \& Van der Voort, M. E. (1984). Ecosystems decay of Amazon forest fragments. In Extinct- ions, ed. M. H. Nitecki. University of Chicago Press, Chicago, pp. 296-325.

Mallinson, J. (1978). The Shadow of Extinction. Macmillan, London.

Mech, L. D. (1989). Wolf population survival in an area of high road density. Amer. Mid!. Nat., 121, 387-9.

Mech, L. D. \& Nelson, E. N. (1990). Evidence of prey-caused mortality in three wolves. Amer. Mid!. Nat., 123, 207-8.

Palomares, F., RodrIguez, A., Laffitte, R. \& Delibes, M. (1991). The status and distribution of the Iberian Lynx Felis pardina in Coto Doñana area, SW Spain. BioL Conserv., 57, 159-69.

Rau, J. R., Beltrán, J. F. \& Delibes, M. (1985). Can the increase of fox density explain the decrease in lynx numbers at Doflana? Rev. Ecol. (Terre Vie), 40, 145-50.

Rodriguez, A. \& Delibes, M. (1992). Current range and status of the Iberian lynx Felis pardina, Temminck 1824 in Spain. BioL Conserv., 61, 189-96.

Rogers, P. M. \& Myers, K. (1980). Animal distributions, landscape classification and wildlife management, Coto Donana, Spain. J. app!. Ecol., 17, 545-65.

Shaffer, M. L. \& Samson, F. B. (1985). Population size and extinction: a note on determining critical population sizes. Amer. Nat., 125, 144-52.

Soriguer, R. C. (1981). BiologIa y dimámica de una población de conejos Oryctolagus cuniculus L. en AndalucIa Occidental. Doñana Acta Vert., 3(3), 1-379.

Trent, T. T. \& Rongstad, O. J. (1974). Home range and survival of cottontail rabbits in southwestern Wisconsin. $J$. Wild!. Manage., 38, 459-72.

Vandewalle, $\mathrm{Ph}$. (1989). Le cycle reproducteur de lapin de Garenne Oryctolagus cuniculus en Camargue: influence des factors environnementaux. Gibier Faune Sauvage, 6, 1-25. 